\title{
PERCEIVED EFFECTS OF SOCIAL MEDIA USAGE ON DEVELOPMENT OF UNDERGRADUATE STUDENTS IN PUNJAB, PAKISTAN
}

\author{
aMuhammad Luqman*, aMuhammad B. Zulfiqar, aMuhammad Yaseen, ${ }^{b}$ Tahir M. Butt, cAyesha Riaz, \\ aMuhammad U. Mehmood \\ a College of Agriculture, University of Sargodha, Pakistan. \\ ${ }^{b}$ Department of Agricultural Extension, University of Agriculture Faisalabad, Sub Campus Depalpur. \\ ${ }^{c}$ Institute of Home Sciences, University of Agriculture Faisalabad, Pakistan.
}

\section{ARTICLE INFO}

\section{Article history}

Received: September 22, 2020

Revised: December 16, 2020

Accepted: December 23, 2020

\section{Keywords}

Perceptions

Social media

Development

Academic performance

Agriculture students

\section{A B S T R A C T}

This study aimed to assess the impacts of social media gadgets on academic performance of the students. The study was conducted in two randomly selected universities in Punjab, i.e., University of Agriculture Faisalabad and University of Sargodha. The sample size for the study was 200 (100 from each university) purposively selected undergraduate students enrolled in B.Sc. (Hons.) Agriculture. Data was collected through the valid, pre-tested and structured questionnaire and analyzed through SPSS. Descriptive statistics was applied for the meaningful interpretation of the results. The results of the study showed that average age of the respondents was 21.09 years. Of the total respondents, $59.8 \%$ belonged to rural areas and $40.5 \%$ belonged to urban areas. Less than half (46\%) of respondents were small farmers and $13.5 \%$ had no land. Most of the respondents $(76.3 \%)$ were owners of their lands. Farming was the key income source for $58 \%$ respondents. Average area under cultivation was perceived 10.61 acres. Regarding use of social media gadgets, $87.5 \%$ of respondents had an account on WhatsApp for contacts and information sharing thus WhatsApp was the widely used gadget $(\bar{x}=3.42 \pm 1.30)$. Pertaining to use of social media gadgets, improved students' confidence ( $\bar{x}=3.28)$, developing high quality multimedia products such as presentations ( $\overline{\mathrm{x}}=3.27)$, enhanced opportunity of discussion ( $\overline{\mathrm{x}}=3.26)$, enforcement and encouragement to independent learning $(\overline{\mathrm{x}}=3.19)$ were the leading impacts as perceived by the respondents on their academic performance. This study affirms the overwhelmed effectiveness of social media and urged universities to develop a framework to integrate social media in educational system.

Corresponding Author: Muhammad Luqman

Email: extensionpak@gmail.com

(C) The Author(s) 2020.

\section{INTRODUCTION}

The overwhelmed adoption of social media tools among youth could be associated with their up-to-date knowledge of ICTs and compatibility with the technology and level of accessibility to different ICT tools (Vorderer et al., 2016). Use of social media tools encourages young individuals, in particular, to receive and retrieve information and connecting with each other to interact for a reason (Obar and Wildman, 2015). Use of social media and ICTs in and out of the classroom activities is mounting across the universities. University students produce a possible way to use social networking tools to 
interact with the concerned administration (Junco et al., 2010). A number of universities across the world have developed their official webpages to escalate the students' access to recent information (Selwyn, 2009). DeAndrea et al. (2012) arbitrated that universities have set their social networking sites in order to facilitate students to socialize and interact with the faculty staff to boost their academic performance as well.

Pakistan possesses a proactive and speedy growing division of Information Communication Technologies, though the potential in the country is not fully explored. Pakistan is graced as a 3rd quickly growing industry in the world. Till 2008, the ICTs sector in Pakistan exhibited triple-digit growth, however speeds slowed down afterwards and rise again in $2010^{1}$. Since then, attention has been paid on a government level to integrate ICTs in various sectors including education. Pakistan is one of the major markets of use of ICTs. In Pakistan, 44.6 million people are internet users, 35 million are active users of social media and 32 million use social media and internet on their mobile phones.

Mustafa (2018) had reported that use of social media in particular influence academic performances of students either way such as positive or negative. However, the positive outcomes on academic achievements are directly linked with the judicious use of different media gadgets. Tahir (2015) had reported that use of modern media tools significantly increased the knowledge level of students. They further arbitrated that media influenced the attitude of students towards learning positively. According to the Khan et al. (2015) majority of the students agreed that use of different ICT tools enhanced their access to literature and helped them to obtain higher grades. In another study, Amin et al. (2016) had concluded a positive association between the use of social media and improvement in academic performance of the students. They further reported that Facebook, Twitter and Skype were the prominent tools being used by the students for academic purposes. Social media showed a key role in encouragement of the students towards learning (Hussain, 2012). However, he further pointed out that inadequate access to internet, power failure and health concerns were the challenges needs to be addressed to enhance the positive stimulation of social media gadgets in the learning

\footnotetext{
${ }^{1}$ Pakistan Telecommunication Authority (PTA) Annual Report 2009-10.
}

proceedings. Tariq et al. (2012) had recommended to regulate social media usage and parents must be advised by the teachers to follow up their students and limit the use of media gadgets. Solid initiatives from the government to streamline social media among students for their bright future could yield the profitable results. In Pakistan, various research studies Hussain (2012), Hasnain et al. (2015), Amin et al. (2016), Mustafa (2018) assessed the social media use, its impacts on the students' academic grades. Mainly the results unveiled negative impression of social media gadgets on the students' academia. In few studies, social media has been held responsible for the emergence of social evils and student's health concerns. The literature mainly focused that social media usage hampers their abilities and disrupt their learning process. However, this logic is unsubstantiated and inadequate to criticize the social media tools use among the students. Previously the studies spotlighted on the negative side and slight on positive avenues of the social media. Over generalizations regarding the impacts of social media tools are visibly not justified. Previous studies were mainly local in nature and conducted on small-scale targeting a small number of sample size and investigating any specific ICT tool. More needs to be investigated about the positive and negative avenues of use of different tools. Therefore, there is a need to conduct a conclusive research study encompassing all ICTs, their impact on academic grades of students in the Pakistan. In this context, this research study was planned to assess the role of ICTs on the academic enactment of undergraduate students enrolled in two leading universities of province Punjab i.e. University of Agriculture Faisalabad and University of Sargodha. This research study emphasized to fill the literature gap regarding influence of ICTs on the academic achievements of students since study of this nature has rarely been conducted in the Pakistani context. This study was mainly focused on assessment of effects of social media use in development of students in Punjab Pakistan.

\section{METHODOLOGY}

This research study was focused on undergraduate students enrolled in different agricultural universities in the Punjab, Pakistan. For selection of two universities as study area a list of agricultural universities was prepared which served as sampling frame and allowed 
researcher to adopt random selection. Thus, through random selection (i) University of Agriculture Faisalabad and (ii) University of Sargodha were selected as study area. All the undergraduate students enrolled in B.Sc. (Hons.) Agriculture at these two universities served as the population for the study.

In order to select sample a purposive sample selection technique was adopted because a vast majority of students is enrolled in the universities and it was not possible to develop a sampling frame and give each student an equal chance of to be selected. Thus, through purposive selection 100 undergraduate students were selected from each selected university thereby making a sample size of 200 undergraduate students.

Respondents were educated therefore questionnaire was used as research instrument to gather information. Research instrument was well in line to objectives of the study and finalized with consultation of experts from department of Extension, University College of Agriculture University of Sargodha. Instrument was pretested on 40 undergraduate students from University
College of Agriculture University of Sargodha. These respondents were other than the respondents selected for final data collection. After pre-testing data were analyzed and necessary changes were made in the instrument. Unnecessary itemed were removed while some important statements were included accordingly. The data were collected by the data collection team consisting of agricultural extension students. Each respondent was given a questionnaire and proper instructions to fill out the questionnaire. Respondents were first taken in confidence and purpose of data was clarified to them. Respondents were assured that anonymity will be maintained. Each respondent was first asked for the consent and provided with the questionnaire accordingly and given vote of thank at the end. Collected data were analysed through Statistical Packages for Social Sciences (SPSS). As the study was mainly quantitative hence descriptive statistics, including frequencies, percentages, means, and standard deviations were calculated to interpret the findings.

\section{RESULTS}

Table 1. Socio-economic attributes of the respondents.

\begin{tabular}{|c|c|c|c|}
\hline Socio-economic attributes of the respondents & $\mathrm{F}$ & $\%$ & Mean \\
\hline Age (in years) & & & 21.09 \\
\hline \multicolumn{4}{|l|}{ Background } \\
\hline Rural & 119 & 59.5 & \\
\hline Urban & 81 & 40.5 & \\
\hline \multicolumn{4}{|l|}{ Size of land holding } \\
\hline Landless & 27 & 13.5 & \\
\hline Small $(<12.5)$ & 92 & 46 & \\
\hline Medium (>12.5-25) & 63 & 31.5 & \\
\hline Large $(>25)$ & 18 & 9 & \\
\hline \multicolumn{4}{|l|}{ Tenancy Status } \\
\hline Owner cultivator & 132 & 76.30 & \\
\hline Tenants & 28 & 16.18 & \\
\hline Owner-cum-tenants & 13 & 7.52 & \\
\hline \multicolumn{4}{|l|}{ Source of Income } \\
\hline Farming only & 116 & 58.0 & \\
\hline Multiple income sources & 84 & 42.0 & \\
\hline
\end{tabular}

Table 1 indicates that average age of a respondent was 21.09 years. This indicates all the respondents were in their productive ages and they could be good receptive of social media gadgets. More than half (59.5\%) respondents belonged to rural areas whereas $40.5 \%$ came from urban areas to study agriculture. Of the total respondents $13.5 \%$ were landless and most of them belonged to urban areas. Among respondents $46 \%$ were small farmers and $31.5 \%$ were medium level farmers. Closely a one in ten respondent was large farmer. Of the total respondents, $76.30 \%$ were owner cultivators and $16.18 \%$ were tenants followed by $7.52 \%$ owner-cumtenants. Greater than half (58\%) respondents had reliance on farming only to generate income whereas 
$42 \%$ respondents were perceived generating income from the multiple income sources along with farming.
Average area under cultivation as reported was 10.61 . This indicates majority of cultivation was on small scale.

Table 2. Social media services as used by the respondents for their learning.

\begin{tabular}{lccccc}
\hline ICTs devices/tools & \multicolumn{4}{c}{ Do you have an account? } \\
\cline { 2 - 5 } & \multicolumn{3}{c}{ Yes } & \multicolumn{3}{c}{ No } \\
\cline { 2 - 5 } & F & $\%$ & F & $\%$ \\
\hline Facebook & 142 & 71.0 & 58 & 29.0 \\
Twitter & 25 & 12.5 & 175 & 87.5 \\
WhatsApp & 175 & 87.5 & 25 & 12.5 \\
LinkedIn & 131 & 65.5 & 69 & 34.5 \\
\hline
\end{tabular}

Table 2 indicates that varying numbers of respondents had an account on Facebook, Twitter, WhatsApp and LinkedIn. Of the total respondents, $87.5 \%$ had an account on WhatsApp for contacts and information sharing. Whereas, the majority (71\%) of the respondents has an account on Facebook. Respondents acclaimed
Facebook a full of information during informal discussion. About $65.5 \%$ of respondents were users of LinkedIn for information sharing and learning. Twitter appeared least preferred and only $12.5 \%$ had an account. Respondents argued that Twitter is more professional and had limited learning opportunities.

Table 3. Extent of use of social media tools as perceived by the respondents.

\begin{tabular}{lcc}
\hline ICTs devices/tools & Mean \pm Standard Deviation & Rank Order \\
\hline Whatsapp & $3.42 \pm 1.30$ & 1 \\
LinkedIn & $3.37 \pm 1.39$ & 2 \\
Twitter & $3.21 \pm 1.25$ & 3 \\
Facebook & $3.10 \pm 1.19$ & 4 \\
\hline
\end{tabular}

Table 3 shows that WhatsApp was the most frequent used information source by the respondents. The extent of use of WhatsApp obtained a mean value of 3.42 and stood on $1^{\text {st }}$ in raking. LinkedIn was the $2^{\text {nd }}$ leading used information source with a mean value of 3.37. Twitter appeared $3^{\text {rd }}$ in the rank order with a mean value of 3.34 .
Facebook was ranked $4^{\text {th }}$ with mean value of 3.10 . The results indicate that students were more inclined toward WhatsApp and LinkedIn. Easy access to the internet and browsing social media on a mobile phone were the leading reasons behind this overwhelmed use of social media gadgets.

Table 4. Distribution of respondents according to their daily study hours and hours of social media use.

\begin{tabular}{lcc}
\hline Distributions & $\begin{array}{c}\text { Number of studying hours } \\
\text { daily basis }\end{array}$ & $\begin{array}{c}\text { Hours of social media use on a } \\
\text { daily basis }\end{array}$ \\
\hline Mean & 2.5 & 4.94 \\
Minimum & 0.6 & 1.00 \\
Maximum & 4.4 & 8.3 \\
Total & 200 & 200 \\
\hline
\end{tabular}

Table 4 shows that an average study hour spent on social media gadgets as reported by the respondents were 2.5. The minimum time spent in studying was 0.6 hour 4.4 hours a day was maximum. Moreover, the average time spent on social media was 4.94. The minimum time spent on social media was 1 hour whereas the maximum was 8.3 hours. Findings showed a significant difference in time spent in studying and using social media. The average time spent on social media is found almost double than the time spent on studying. 
Table 5. Effects of social media use as perceived by the respondents.

\begin{tabular}{lcc}
\hline Perceived effects & Mean \pm SD & Ranking \\
\hline Improved students' confidence & $3.28 \pm 1.55$ & 1 \\
Permits students to yield high-quality multimedia products & $3.27 \pm 1.53$ & 2 \\
Enhanced opportunity of discussion & $3.26 \pm 1.32$ & 3 \\
Encourages independent learning & $3.19 \pm 1.29$ & 4 \\
Increases the motivation of students through practical activity & $3.19 \pm 1.35$ & 5 \\
Motivated students to learn and participate in learning activities & $3.18 \pm 1.61$ & 6 \\
Increases information reliability and accuracy & $3.16 \pm 1.36$ & 7 \\
Time-saving & $3.16 \pm 1.80$ & 8 \\
Develops communication skills and awareness of different audiences & $3.08 \pm 1.22$ & 9 \\
Improved modes of presentation & $3.07 \pm 1.28$ & 10 \\
Enables collaborative learning & $3.01 \pm 1.24$ & 11 \\
Access to real-world information through the Web & $2.97 \pm 1.45$ & 12 \\
Provides realistic and up-to-date information & $2.96 \pm 1.33$ & 13 \\
Gives students more control over literature & $2.94 \pm 1.45$ & 14 \\
Balances individual differences and enable students to meet special needs & $2.89 \pm 1.26$ & 15 \\
Has enhanced achievement due to the reinforcement and practice that ICT has & $2.88 \pm 1.69$ & 16 \\
afforded. & & \\
Increased student teacher interaction & $2.81 \pm 1.60$ & 17 \\
Increased the quality of student work and practical examples through visualization & $2.74 \pm 1.13$ & 18 \\
Improves language skills through word processing & $2.74 \pm 1.18$ & 19 \\
Encourages the use of peer coaching and peer reviews & $2.71 \pm 1.22$ & 20 \\
\hline
\end{tabular}

Table 5 shows the impact of the use of social media gadgets in academic performance of the undergraduate students. The profound and significant impacts as perceived by the respondents was an increase in level of confidence of the students by the use of social media tools. Improved students' confidence in the result of social media use obtained mean value of 3.28 and $1^{\text {st }}$ rank. Respondents further perceived that pertaining to use of social media they were more able to develop highquality multimedia products such as presentations and assignments. This impact was ranked $2^{\text {nd }}$ with a mean value of 3.27 .

Among various impacts, another positive impact perceived by the respondents was an enhanced opportunity of discussion within students' groups and teachers followed by the enforcement and encouragement to independent learning. Both of these impacts were ranked $3^{\text {rd }}$ and $4^{\text {th }}$ on rank order with a mean value of 3.26 and 3.19 respectively. Findings are supported with the stance of Asur and Huberman (2010) where they reported that modern technologies have affected the way of human interaction by changing the way we interact face to face, how we get information and the dynamic of social groups and the friendship. Use of modern tools helped students to learn through hand-on exercises and practical activities. Thus, the impact on increasing students' motivation through hand-on activities obtained $5^{\text {th }}$ rank and mean value of 3.19.

The mean values of the benefits ranged from 1 to 11 ranged between 3.00 and 4.00 . This implies that the impact of social media tools falls in the medium level category. As the mean value heads to higher, the impact will increase accordingly. It can be said, so far students are not enjoying the best potential of social media tools to improve their academic learning.

Apart from the top-ranked impacts, various other impacts were perceived by the respondents as well. But, the impact of these avenues remained less than medium level. The mean values obtained by the impacts as perceived by the respondents remained less than 3 . For example, access to real-world information, providing realistic and latest information, offering control over literature, addressing special needs, increasing studentteachers relationship, improvement in language skills and encouragement for peer coaching and peer reviews were the least perceived impacts and creating room to work on these areas for the development and facilitation of students. 


\section{DISCUSSION}

From the response of the participants of this study it is very much clear that majority of them are beholder of small-scale land. Respondents argued that Twitter is more professional and had limited learning opportunities. Findings are more or less similar to those of Owusu-Acheaw and Larson (2015) where they found that $66.4,19.9,6.2 \%$ respondents were known to Facebook, WhatsApp and Twitter. Finding are further similar to those of Schneider (2010) where he made the assertion that around $85 \%$ of undergraduate students were Facebook users. This ascertains that recently they are and they could be an integral part in the promotion of social media usage as supportive network for farming. Students were more inclined toward WhatsApp and LinkedIn because they use acquire the information from direct or reliable source. Easy access to the internet and browsing social media on a mobile phone were the leading reasons behind this overwhelmed use of social media gadgets. The average time spent on social media is found almost double than the time spent on studying. Findings of the Owusu-Acheaw and Larson (2015) reported that $66.3 \%$ of respondents spent $30-60$ minutes on social media while $1.5 \%$ respondent spent between 4-5 hours a day on social media sites. This showed the popularity and interest of students in social media. Choney (2010) argued that pertaining to mounting popularity of the social media, teachers and economists are questioning whether grades of the students wouldn't be affected by how much time they are consuming on social media. Mehmood and Taswir (2013) further substantiated this and report that the use of the internet is one of the leading factors that can impact the academic performance of students either positively or negatively.

Use of social media motivated students to learn and to participate in learning activities and increased information reliability and accuracy. Respondents further reported that the use of social media to access information for learning is a time-saving process. Being time-saving obtained $8^{\text {th }}$ rank and mean value of 3.16 . Online courses, video tutorials and lectures helped students to improve their communication skills and awareness about the knowledge on different avenues. Sheldon (2008) stated that half of the college students browse social networking sites several times a day to interact with the latest knowledge. This impact was ranked 9th with a mean value of 3.8. Respondents further opined that the use of social media tools improved their ways of presentation in the class and ranked this benefit $10^{\text {th }}$ on the scale with a mean value of 3.07. Use of social media further guided students toward collaborative learning through different social media pages like WhatsApp groups and Facebook pages. These benefits of collaborative learning were ranked $11^{\text {th }}$ with a mean value of 3.01 .

\section{CONCLUSION AND RECOMMENDATIONS}

This study summarizes that social media has become a powerful tool and pertaining to its use students had improved their academic performance. Students are connected to the different knowledge sources every time. Accessing literature, friends, discussion forums and teachers for the instruction has become easier now. Social media use improved students' confidence, computer skills, presentation skills and gave them confidence of interaction. Among other perceived impacts access to real world information, providing realistic and latest information, offering control over literature, addressing special needs, increasing studentteachers relationship, improvement in language skills and encouragement for peer coaching and peer reviews were prominent. Thus, study concludes that use of social media has significant impact on academic performance of the students on universities level. However, Universities should develop a framework for effective use and integration of social media inside classrooms.

\section{ACKNOWLEDGEMENTS}

The researchers acknowledge the contribution of agricultural graduates from University of Agriculture Faisalabad and College of Agriculture, University of Sargodha. Taking time for recording their response with questionnaire is much appreciated and much valued.

\section{REFERENCES}

Amin, Z., A. Mansoor, S. R. Hussain and F. Hashmat. 2016. Impact of social media of student's academic performance. International Journal of Business and Management Invention, 5: 22-29.

Asur, S. and B. A. Huberman. 2010. Predicting the Future with Social Media 2010 IEEE/WIC/ACM International Conference on Web Intelligence and Intelligent Agent Technology. IEEE.

Choney, S. 2010. Facebook use can lower grades by 20 percent, study says. NBC Bay Area. 
DeAndrea, D. C., N. B. Ellison, R. LaRose, C. Steinfield and A. Fiore. 2012. Serious social media: On the use of social media for improving students' adjustment to college. The Internet and Higher Education, 15: 15-23.

Hasnain, H., A. Nasreen and H. Ijaz. 2015. Impact of social media usage on academic performance of university students 2nd International Research Management \& Innovation Conference (IRMIC).

Hussain, I. 2012. A Study to Evaluate the Social Media Trends among University Students. Procedia Social and Behavioral Sciences, 64: 639-45.

Junco, R., G. Heiberger and E. Loken. 2010. The effect of Twitter on college student engagement and grades. Journal of Computer Assisted Learning, 27: 119-32.

Khan, J., Z. K. Malik and S. Amin. 2015. The Impact of Mobile Phones on the Performance of University Students. Research Journal of Humanities and Social Sciences, 6: 61.

Mehmood, S. and T. Taswir. 2013. The effects of social networking sites on the academic performance of students in college of applied sciences, Nizwa, Oman. International Journal of Arts and Commerce, 2: 111-25.

Mustafa, S. 2018. A Descriptive Study for the Impacts of Using Social Media on the Studies of University Students in Pakistan (A Literature Review.). European Scientific Journal, ESJ, 14: 18.

Obar, J. A. and S. Wildman. 2015. Social media definition and the governance challenge: An introduction to the special issue. Telecommunications Policy, 39: 745-50.

Owusu-Acheaw, M. and A. G. Larson. 2015. Use of social media and its impact on academic performance of tertiary institution students: A study of students of Koforidua Polytechnic, Ghana. Journal of Education and Practice, 6: 94-101.

Schneider, N. 2010. Facebook, Other Social Network Sites Could Lead to Lower Grades for Students. Link: http://www. associatedcontent. com/article, 1650000.

Selwyn, N. 2009. Faceworking: exploring students' education-related use of Facebook. Learning, Media and Technology, 34: 157-74.

Sheldon, P. 2008. The relationship between unwillingness-to-communicate and students' Facebook use. Journal of Media Psychology, 20: 67-75.

Tahir, M. 2015. The impact of electronic media on youth behvaiour regarding informal education in Peshawar KPK City University Research Journal, 5.

Tariq, W., M. Mehboob, M. A. Khan and F. Ullah. 2012. The impact of social media and social networks on education and students of Pakistan. International Journal of Computer Science Issues (IJCSI), 9: 407.

Vorderer, P., N. Krömer and F. M. Schneider. 2016. Permanently online - Permanently connected: Explorations into university students' use of social media and mobile smart devices. Computers in Human Behavior, 63: 694-703.

Publisher's note: EScience Press remains neutral with regard to jurisdictional claims in published maps and institutional affiliations.

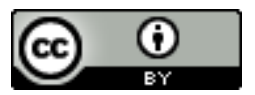

Open Access This article is licensed under a Creative Commons Attribution 4.0 International License, which permits use, sharing, adaptation, distribution and reproduction in any medium or format, as long as you give appropriate credit to the original author(s) and the source, provide a link to the Creative Commons license and indicate if changes were made. The images or other third-party material in this article are included in the article's Creative Commons license, unless indicated otherwise in a credit line to the material. If material is not included in the article's Creative Commons license and your intended use is not permitted by statutory regulation or exceeds the permitted use, you will need to obtain permission directly from the copyright holder. To view a copy of this license, visit http://creativecommons.org/licenses/by/4.0/. 